\title{
Anne DUNAN-PAGE, Marie-Christine MUNOZ-TEULIÉ, (Textes réunis par), Les Huguenots dans les îles britanniques de la Renaissance aux Lumières. Écrits religieux et représentations
}

Paris, Honoré Champion, 2008, 266 p.

\section{Daniel Vidal}

\section{(2) OpenEdition \\ Journals}

Édition électronique

URL : http://journals.openedition.org/assr/21119

DOI : 10.4000/assr.21119

ISSN : $1777-5825$

Éditeur

Éditions de l'EHESS

Édition imprimée

Date de publication : 31 décembre 2009

Pagination : 75-342

ISBN : 978-2-7132-2218-4

ISSN : 0335-5985

\section{Référence électronique}

Daniel Vidal, « Anne dunAN-PAge, Marie-Christine munoz-TEulté, (Textes réunis par), Les Huguenots dans les Îles britanniques de la Renaissance aux Lumières. Écrits religieux et représentations », Archives de sciences sociales des religions [En ligne], 148 | octobre-décembre 2009, document 148-45, mis en ligne le 19 mai 2009, consulté le 21 septembre 2020. URL : http://journals.openedition.org/assr/21119 ; DOI : https://doi.org/10.4000/assr.21119

Ce document a été généré automatiquement le 21 septembre 2020.

(c) Archives de sciences sociales des religions 


\section{Anne DUNAN-PAGE, Marie-Christine MUNOZ-TEULIÉ, (Textes réunis par), Les Huguenots dans les îles britanniques de la Renaissance aux Lumières. Écrits religieux et représentations}

Paris, Honoré Champion, 2008, 266 p.

Daniel Vidal

\section{RÉFÉRENCE}

Anne DUNAN-PAGE, Marie-Christine MUNOZ-TEULIÉ, (Textes réunis par), Les Huguenots dans les Îles britanniques de la Renaissance aux Lumières. Écrits religieux et représentations, Paris, Honoré Champion, 2008, 266 p.

1 Si les «refuges " genevois, hollandais ou en terres allemandes ont été abondamment étudiés, chiffrés et historiés, l'émigration dans l'espace britannique de milliers de huguenots fuyant au fil des siècles les persécutions de leur Église n'a sans doute pas connu, dans les dernières décennies, d'analyses exhaustives à la mesure de son importance. Les études françaises de référence datent (Ch. Weiss, 1853 ; F. de Schickler, 1892). L'ouvrage de Bernard Cottret, Terre d'exil. L'Angleterre et ses réfugiés français et wallons... (1550-1700), (1985) n'intègre pas dans son champ de recherche l'émigration suivant la Révocation et les conversions forcées et dragonnades. Le colloque international organisé à Montpellier en mars 2004, d'où procède l'ouvrage actuel, ne constitue pas pour autant une étude globale et systématique du mouvement réfugié en son ensemble, mais, à partir de quelques cas particuliers et exemplaires, le témoignage 
de son inscription dans l'espace politico-culturel du pays d'accueil. Espace complexe, à polarités antagonistes ou du moins divergentes, partagé entre le primat de l'Église anglicane, la constitution d'allégeances dissidentes, et la réception de membres de l'Église Réformée. Anne Dunan-Page et Marie-Christine Munoz-Teulié ne manquent pas de souligner le paradoxe, au-delà des bouleversements politiques, de la position d'une monarchie réprimant toute « chapelle » sécessionniste, et accueillant les représentants d'un protestantisme français qui devait sans doute lui apparaître suspect. Aussi bien la charte de juillet 1550 assujettissait-elle l' «église française " à l'Église d'Angleterre, le souverain détenant l'autorité ultime. Tel est le cadre très général dans lequel s'inscrivent les interventions concernant quelques aspects singuliers du refuge britannique, sur les plans culturels, des controverses religieuses et identitaires, et de leur arrière-fond politique.

2 Le Refuge peut être occasion de traductions/modifications de textes élaborés en France et reconduits en Angleterre, sous des formes adaptées aux conditions du temps, afin de délivrer un message différent de l'original. En 1571, Georgette de Montenay (1540-1581) publie ses Emblèmes ou devises chrétiennes, en français, puis en latin, qui seront diffusés dans les grands centres Réformés européens. Protestante, familière de la cour de Jeanne d'Albret, sa cousine, l'auteure avait pour dessein, par cette centaine d'emblèmes et leurs accompagnements poétiques, de célébrer la doctrine de Calvin, et plus précisément l'impérieuse notion de salut, tout en traitant des persécutions dont étaient victimes les « religionnaires ». Emblèmes et devises furent repris et recyclés, quarante ans plus tard, par Esther Inglis [Langlois] (1571-1624), calligraphe et copiste protestante réfugiée en Écosse, qui, par substitutions successives des portraits et figures, adresse un message d'autre teneur. Selon Marie-Claude Tucker, analysant les transitions iconographiques de l'un à l'autre ouvrages, il s'agit moins, pour Esther, d'avertir le peuple huguenot des dangers qui le menacent, que de séduire un public lettré, tout en évoquant les difficultés grandissantes du calvinisme en terre de refuge, et, contre la pression grandissante de la romanisation, en rappelant cette "pure expression de la pensée calviniste ": l'intervention permanente de Dieu. Moins donc opération de travestissement, qu'adaptation «militante » d'un recueil d'emblèmes à des circonstances politiques en bouleversement. L'analyse croisée par Richard Hillman de la tragédie de Christopher Marlowe, The Massacre at Paris (1593), inspirée de la SaintBarthélemy, et des œuvres de Du Bartas , montre les « influences alternées ", d'îles en Continent, qui constituent la figure du martyr, plus individualisée et tragique chez l'auteur rebelle de L'Histoire du docteur Faust, plus collective et témoignant d'un destin funeste chez le poète protestant. À coup sûr, la personnalité de Claude de Sainliens, présentée par Laurent Barec, ne participe ni de cette tragédie, ni de ce destin. Exilé à Londres en 1564, ce huguenot tient plus d'un personnage balzacien avant l'heure, que d'un protestant vêtu d'humilité candide... Spécialiste de linguistique française, animé d'une "volonté farouche de réussite financière", il déploiera tous ses talents d'enseignant et de fondateur d'école privée, pour se faire une place - très vite centrale -, dans les milieux de l'éducation des classes moyennes, commerçants et juristes, avides de reconnaissance culturelle par le maniement aisé de la langue française encore auréolée de prestige. Et de tout un humanisme que le pédagogue venu de France pouvait leur proposer, à travers Térence, Horace, Virgile, etc. Surprenante histoire, et jubilatoire, d'un Rastignac venu d'une Réforme encore étonnée, sans doute, d'avoir nourri en son sein un tel héritier... ! 
3 Les rapports de le Réforme aux pouvoirs politiques furent, dans les faits, toujours déchirés entre impératif de fidélité au souverain, et devoir d'une conscience parfois contrainte à l'insoumission. Plusieurs controverses survenues au Refuge britannique s'inscrivent dans cette double exigence. La famille Du Moulin, par ses lignées quasiment " héréditaires » de pasteurs et d'érudits, a formé, de la Renaissance aux Lumières, un réseau actif dans les allées du pouvoir, dont Christine Ronchail retient quelques exemples. Pierre I (1568-1658), défenseur de l'orthodoxie réformée, est invité par Jacques $1^{\mathrm{er}}$, roi d'Angleterre et d'Écosse, pour faire aboutir son projet de réunion des Églises. Il entre aussitôt en polémique avec Nicolas Coëffeteau, vicaire général des dominicains, sur le problème capital du serment de fidélité et d'allégeance, contre l'injonction du pape Paul V. Ce qui lui vaut la protection royale, et de participer à la discussion concernant le rapprochement des Églises «ayant secoué le joug de Rome » sans que soit mise en cause la primauté du souverain. Les polémiques politiques entre ses fils Pierre II et Louis, opposent deux itinéraires et personnalités très différents. Pierre, pasteur comme son père, et comme lui proche du pouvoir royal (Charles $\mathrm{I}^{\mathrm{er}}$ et II), mais sans grand relief. Louis, médecin, traducteur, proche des Indépendants et de Cromwell, anti-anglican. Au grand dam de sa parentèle légitimiste. Une allégeance religieuse partagée, mais qui induit des options politiques divergentes. Dans les références de Louis Du Moulin : Milton (1608-1674), d'abord anglican, qui abandonnera ensuite la prêtrise. Christophe Tournu présente le débat du poète majeur avec Claude Saumaise (1588-1653), converti à la Réforme, érudit, philologue, professeur à Leyde. Quand Milton justifie le tyrannicide, et l'exécution de Charles $I^{\text {er }}$ en 1649, Saumaise publie l'année suivante l'apologie du souverain déchu. Il n'est de roi que de droit divin, et le transfert de souveraineté du peuple au roi est «irrévocable». Milton prône le droit naturel des peuples à "l'autodétermination», et la capacité de l'homme à " corriger sa nature » par ses propres moyens. Il ne s'oppose pas à la monarchie en tant que telle, analyse Ch. Tournu, mais à sa "dérive tyrannique " et son caractère héréditaire. Le peuple, par son Parlement, est libre de destituer son roi. Saumaise mot pour mot s'oppose à la conception miltonienne. Le peuple n'est que populace; le roi ne saurait être soumis à la loi, puisqu'il a responsabilité de justice et de religion - tous arguments que certains adeptes de Calvin n'avaient pas manqué de développer sur le Continent. Si Milton parlant du peuple, entend sans doute quelque aristocratie d'« hommes vertueux », il pose la nécessité d'une séparation stricte entre Église et État. De se déployer en un contexte "britannique", la controverse entre le réfugié de Hollande et l'homme Milton, poète et politique, prend une dimension européenne, et participe dès lors des grands débats préparant la raison des Lumières.

4 De Londres, appel fut fait à Pierre I Du Moulin, pour traiter de l'unification des Églises hors de Rome, et dispersées. En sens inverse, les religionnaires de France dépêchent à Londres l'un des leurs pour " émouvoir la charité » des Puissances à l'égard des réfugiés ou des huguenots en péril au royaume de France Tel est le cas de Jean de Convenent (1665-1724), pasteur en Hollande puis à Orange, sa ville natale, et apparenté à une autre famille huguenote de long héritage, les de Chambrun. Françoise Moreil analyse la «mission» de ce pasteur-diplomate auprès du souverain d'Angleterre et prince d'Orange, en faveur de ses "concitoyens" et des réfugiés orangeois de Genève. Convenent rédige et publie d'abord en anglais (1703) puis en français (1704) un ouvrage-témoin des tourments de sa cité, Histoire abrégée des dernières Révolutions arrivées dans la Principauté d'Orange, suivi de réflexions sur les troubles des Cévennes, d'une liste de réfugiés orangeois, et d'un sermon. Ce Théâtre des Révolutions est un récit 
de belle précision historique et descriptive, mais récit également « engagé ». F. Moreil note par exemple le jugement très négatif porté par Convenent sur le prince de Conti et le comte de Grignan, nouvelles autorités temporelles et spirituelles avec lesquelles les réformes d'Orange doivent désormais composer. Trop d'hostilité à leur égard, marquée par l'un de ses pasteurs, risquait de mettre la communauté en péril, et elle s'en alarma. Mais Convenent ne semble obéir, en cette mise au clair de ses propres sentiments, qu'à un devoir de vérité, propre, au demeurant, à "émouvoir» le souverain anglais. D'autant, précise F. Moreil, qu'il n'est pas homme à se payer de mots : "style sobre ", dépourvu de tout "pathos", et, chose remarquable, sans citation biblique aucune. Un document en tous points significatif d'une démarche mûrie et réfléchie. Il y a du Thomas en cet homme, qui ne décrit que ce dont il fut témoin oculaire, répugnant à solliciter des faits qu'il n'aurait connus que de source tierce. Mais des événements de 1685 et 1703 (révocation de l'édit de Nantes, occupation puis réunion de la principauté à la France), le pasteur fut témoin. Si Orange lui paraît une sorte de Canaan, cette « terre promise » n'en fut pas moins le théâtre de violences religieuses. Convenent n'en dit rien, mais n'hésite pas à porter un avis favorable sur les "mécontents" des Cévennes, alors en pleine insurrection. Ce qui lui vaut le courroux des bonnes âmes craignant pour leur salut temporel. Cet ouvrage : un texte de combat, dans une écriture sans emphase. Puritaine?

Nulle emphase, non plus, dans les prophéties énoncées à Londres puis en Europe par les inspirés cévenols en fuite. Mais de l'enthousiasme, plus qu'il n'en fallait sans doute en un espace longuement assagi. La présentation par Yves Krumenacker du mouvement "prophétique » d'origine camisarde et de sa résonance dans les milieux londoniens se fonde sur d'autres études patientes, socio-historiques, consacrées depuis une trentaine d'années à ce phénomène, qui avaient bien en effet noté toute son importance symbolique et politique, ainsi que sa progressive prise en charge par les inspirés anglais. Et qui avaient déjà souligné que la « société » des «French Prophets » devait très vite apparaître plus «inspirée " que véritablement "française ». Du Refuge londonien au XVIII ${ }^{\mathrm{e}}$ siècle, Pauline Duley-Haour remet en mémoire la figure encore trop méconnue du théologien Genevois Jacques Serces, pleinement assimilé à la communauté d'accueil anglaise, en sa centralité politico-ecclésiale, sans qu'en fût affaiblie sa foi huguenote. En contacts étroits avec Benjamin du Plan et Antoine Court, Serces prend une part active, au sein du Comité londonien de secours aux «Églises sous la Croix", dans le soutien aux religionnaires persécutés sur le Continent. De la Renaissance aux Lumières, des acteurs aussi différents que Georgette de Montenay et Esther Inglis, Pierre du Moulin et Sainliens, Milton et Saumaise, Jean Convenent, Elie Marion le prophète, Jacques Serces le théologien, composent un tableau assez singulier pour inviter à une interprétation renouvelée du Refuge, qui fut épreuve de déracinement, mais qui eut en même temps, comme le souligne Hubert Bost en son avant-propos, "un effet catalyseur sur la 'crise de la conscience européenne' ». Le débat Milton-Saumaise, aussi bien que la réactivation de foyers "prophétiques " et d'insoumission théologique au cœur de l'Europe, en constituent sans aucun doute des moments essentiels. 